\title{
Modern design of light steel facades in normal and fire conditions
}

\author{
Katarzyna Rzeszut ${ }^{1, *}$, Andrii Voronoi $^{2}$ \\ ${ }^{1}$ DSc., Poznan University of Technology, Institute of Structural Engineering, Marii Skłodowskiej- \\ Curie 5, 60-965 Poznań, Poland, \\ ${ }^{2}$ M.Sc. (Ph.D. student): Poznan University of Technology, Institute of Structural Engineering, Marii \\ Skłodowskiej-Curie 5, 60-965 Poznań, Poland.
}

\begin{abstract}
In this paper, numerical analysis of bearing load capacity of steel facade cassettes with special perforation in various geometrical configurations was carried out. Particular attention was focused on the influence analysis of the blade inclination and perforation pattern on the structural behaviour. The mechanical response was tested using two separate types of numerical analysis. First contains the analysis under high temperature using coupled thermal-structural analysis according to the nominal temperature-time External curves. In this study nonlinear physical relationships are taken into account, thus influence of high temperature on material properties is assumed. In order to investigate the wind action influence on the cassettes with respect to different blade inclination, the static was provided. The scope of the study includes the preparation of advanced numerical 3D model of thin-walled steel cassettes K1 produced by "Blachy Pruszynski" company using shell finite elements (FE) in Abaqus program.
\end{abstract}

\section{Introduction}

Nowadays, the most common architectural and constructional solution of light external wall cladding systems are trapezoidal sheets and sandwich panels. However, in order to meet the principles of sustainable development and the possibility of using modern architectural and construction solutions, it is more and more common to use different types of cassettes and metal panels. Creative use of metal on facades can be seen in various solutions in the building sector, for example: schools and universities, airports and stations, sports stadiums, entertainment arenas, shopping centres and more. The facades made of such steel panels are classified as thin-walled structures, which create so-called systems of light metal facades. In addition to their structural function, they also play an important aesthetic role. Often, panels and perforated panels are used to distinguish and display the individual character of the building. Perforation of external surfaces enables the introduction of light effects on the facades of the building, which give a new, changing in time, architectural expression of the building. The advantage of this solution, in addition to flexible aesthetic values, is the lower self-weight of the façade. For example, in the city of Wroclaw, Poland,

* Corresponding author: katarzyna.rzeszut@put.poznan.pl 
the PKS bus station and the shopping center "Wrocłavia", received a façade with perforated cassettes of company "Blachy Pruszynski". This solution was introduced in order to highlight the façade in the night time, which significantly emphasizes the individuality of the building. On the other hand, the disadvantage of such façades is the poorly recognized mechanism of structural behaviour in the conditions of normal use as well as in a fire situation. Nevertheless, in recent years, more and more scientific studies deal with issues related to the design of façades made of metal cassettes. In example [1] authors conducted experimental tests and numerical analyses of bearing capacity and stiffness of facade cassettes. The form of deformation of cassette claddings subjected to the wind pressure and suction was specified. In addition, methods for determining the load-bearing capacity of elevation cassettes have been developed, taking into account the support conditions in the form of fixed point and elastic supports. This problem was also discussed by GalewskaUrbańska [2]. The scientific publications related to the design of metal cladding sheets in fire conditions are rarer, but an example of , this subject is discussed,-in the work [3], where $\mathrm{Lu}$ et al. presented numerical simulation of catenary action in cold-formed steel sheeting in fire conditions. In [4] Lu et al. consider the collapse mechanism of the joint between roof cladding and purlins in fire conditions. The deterioration of mechanical properties, such as yield strength and modulus of elasticity, and the evolution of thermal properties, such as thermal conductivity, thermal elongation and specific heat, with temperature of cold-formed steel structural elements in fire are presented in [5]. This issue is very important because the thermal expansion of steel cladding elements may be partially constrained, which may result in thermal stresses, and cause significant deformation and even damage of whole façades. Keeping in mind that the façades, as well as the loadbearing elements of the building, should ensure the integrity of the building in normal and exceptional conditions, the question arises: is the use of perforated elements due to their load capacity and stability in fire conditions safe in relation to non-perforated cassettes. Fire and mechanical wind load can cause large material and geometric deformations, which may result in loss of life or property. Therefore, the proper design of metal cassettes requires the use of various types of calculation procedures described in [6], taking into account different physical phenomena and allowing for correct modelling of the thermalmechanical response of the structure.

\section{Problem formulation}

The main objective of this analysis is an understanding of the thermal and structural behaviour of the thin - walled steel cladding cassettes with perforation in normal and in fire situation. Particular attention is focused on the analysis of the influence of blade inclination and perforation pattern on the structural behaviour. To this purpose the $3 \mathrm{D}$ numerical model of thin-walled steel cassettes allowing for introduction of inclined blades in the perforated part using shell finite elements (FE) in the Abaqus program is developed. The scope of the study includes three types of cassettes: two with perforation (type A, type B) and one without perforation (type C). The numerical analyses cover the heat transfer and coupled thermal - stress analysis, which refer to fire situation. Note, that in the fire conditions the steel elements are subjected to significant thermal expansion and degradation of the material [7], which can cause additional stresses. In order to investigate structural behaviour of the cassettes in normal situation, the static analysis under the wind action with respect to different inclination of blades, is perform. 


\section{Numerical model}

In engineering practice, steel façade cassettes are available as a curved and straight panel with different perforation pattern. In this work, the cassette of the straight panel is subjected to analysis. The cassette's geometry is modelled without any simplifications on the basis of "Blachy Pruszynski" catalogues data. In numerical model, the cassette with dimensions of $880 \times 2780 \times 50 \mathrm{~mm}$ (width $\times$ height $\times$ depth) and sheet thickness of $1.2 \mathrm{~mm}$ is taken into account. In order to reduce the number of finite elements, and hence the calculation time, the height of the cassette is reduced twice. The final geometry is characterized by the parameters: $880 \times 1390 \times 50 \mathrm{~mm}$. Two types of perforation are considered: A - circle with a diameter of $250 \mathrm{~mm}$, rotation of $15^{\circ}, 30^{\circ}$ and $45^{\circ}$ with respect to the panel plane (Fig. 1a, and Fig. 2); B - circle with a diameter of $250 \mathrm{~mm}$ without rotation (Fig. 1b, and Fig. 2).

a)

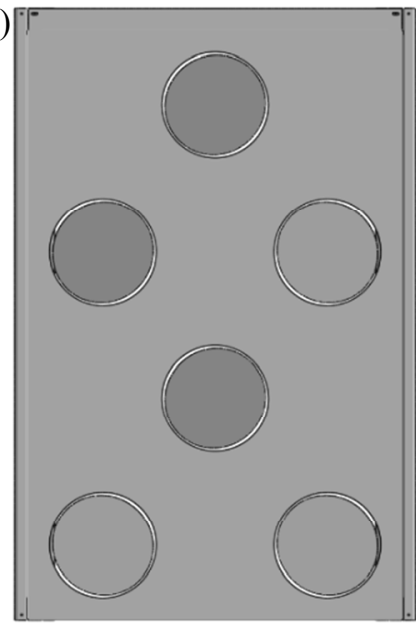

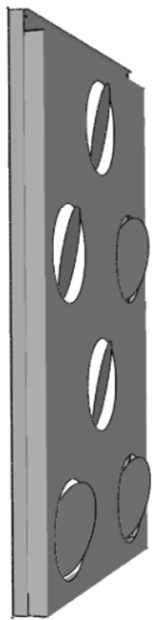
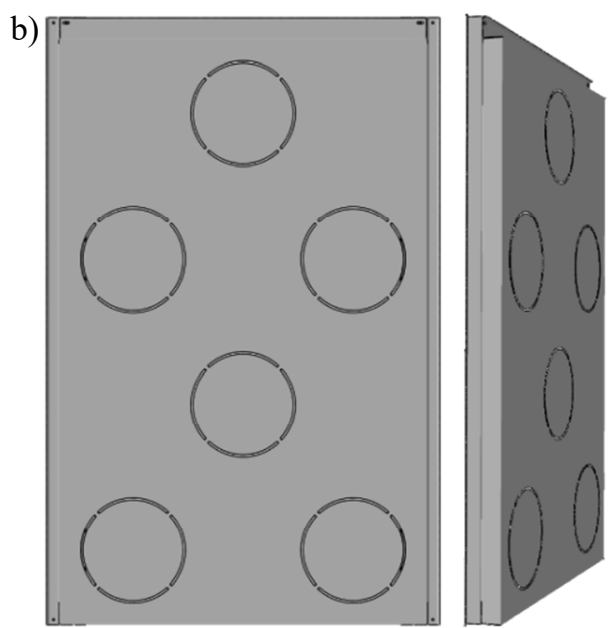

Fig. 1. Planar view of cassette with perforation: a) type A; b) type B.

Figure 2 shows a planar view and cross-sections through perforations.

a) Type A

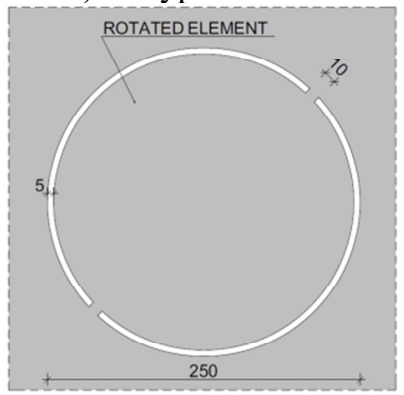

Type B

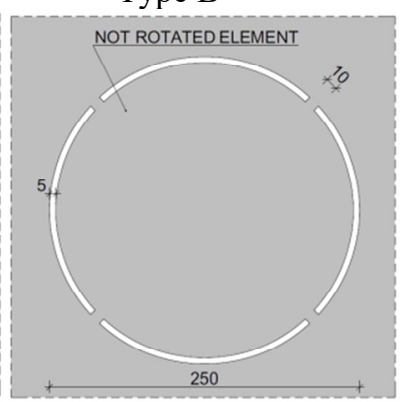

b) Type $\mathrm{A}$

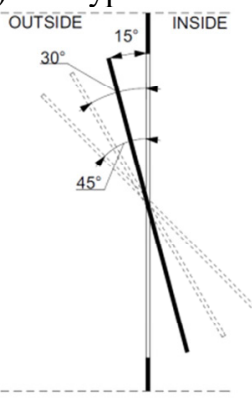

Type B

OUUTSIDE- TINSIIDE

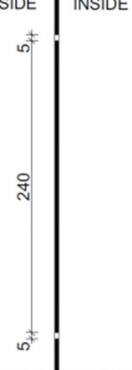

Fig. 2. Constructional details of the coffer part: a) Planar view of perforation type A and B; b) crosssection through perforations type A and B.

The lower and upper edge of the cassettes cooperates with each other through the lock, which is schematically shown in Figure 3a. Such a solution was introduced to ensure free deformation in the cassette panel. In order to take into account the influence of the lock, in the numerical model, at the top and bottom side of the main panel of the cassette additional fragments of cassette were added (Fig. 3b). 
a)

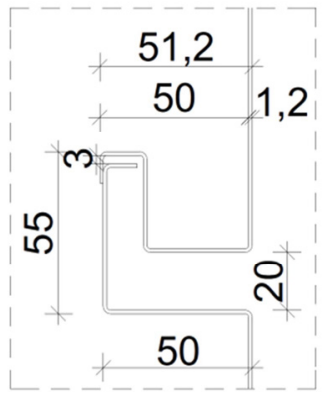

b)

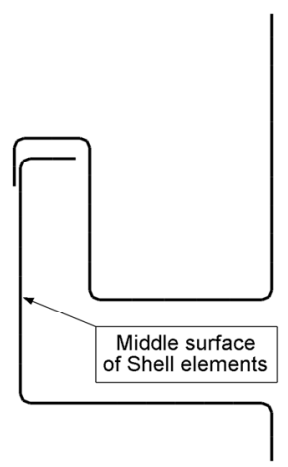

Fig. 3. Constructional details of the lock: a) sketch; b) numerical model.

The material of steel sheeting is S280GD $+Z$, i.e. the nominal yield strength $280 \mathrm{~N} / \mathrm{mm}^{2}$ and nominal ultimate strength $360 \mathrm{~N} / \mathrm{mm}^{2}$. For the structural analysis the nominal stressstrain curve is transformed to the true stress-strain curves. One, homogenous section is used to assign material properties to the elements. The International System of units $(S I)$ is used in the following sections to describe the model. The thermal analysis is provided using nonlinear temperature-dependent material properties: thermal conductivity, specific heat, yield strength ultimate strength and elastic modulus [8].

For heat-stress analysis, the boundary conditions are modelled to reflect real structural support conditions. In this model, the substructure made of Omega 50/30 profile is constrained as shown in Figure 4a. The cassette $\mathrm{K} 1$ is connected to the Omega profile by Multi Point Constraint type "Beam". For static analysis, the substructure is removed from the numerical model; and instead of it, the boundary conditions are modelled in a simplified way using mechanical boundary conditions by imposing constraints on displacement in the perpendicular direction to the panel $(\mathrm{U} 1=0)$, as shown in Figure $4 \mathrm{~b}$.

a)

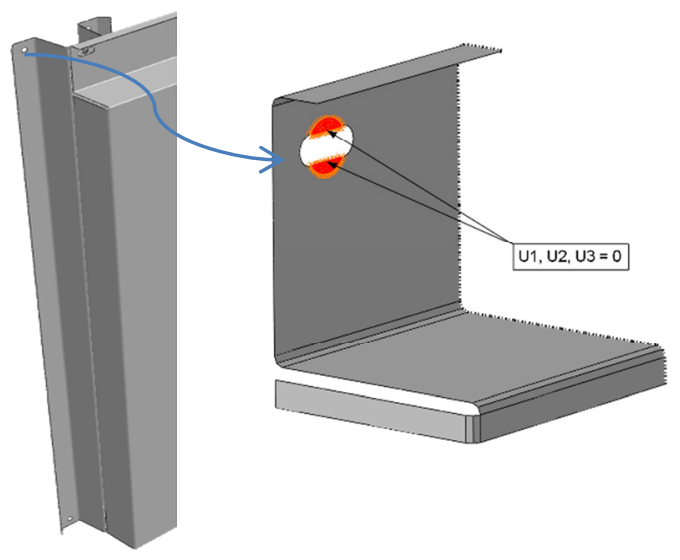

b)

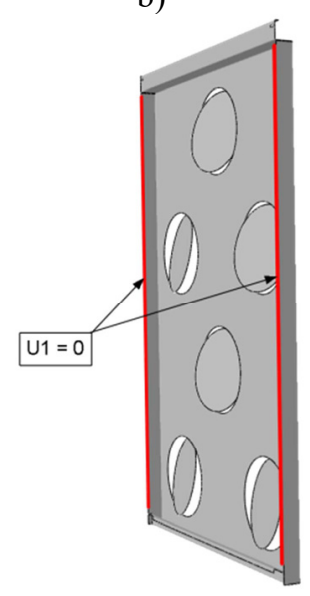

Fig. 4. Details of boundary conditions: a) heat-stress analysis -with substructure made of Omega $50 / 30 ;$ b)static analysis - mechanical boundary conditions.

For the uncoupled heat transfer analysis, thin-walled façade cassette and Omega profile are meshed using 4-node quadrilateral Heat Transfer Shell Finite Elements DS4. For the structural analysis the cassette and Omega profile are meshed using 4-node doubly curved FE Shell Elements S4R with reduced integration. The approximate global sizes of FE 
is $6 \mathrm{~mm}$. The compaction of the FE mesh is done in place of the position of the holes as shown in Figure 5.
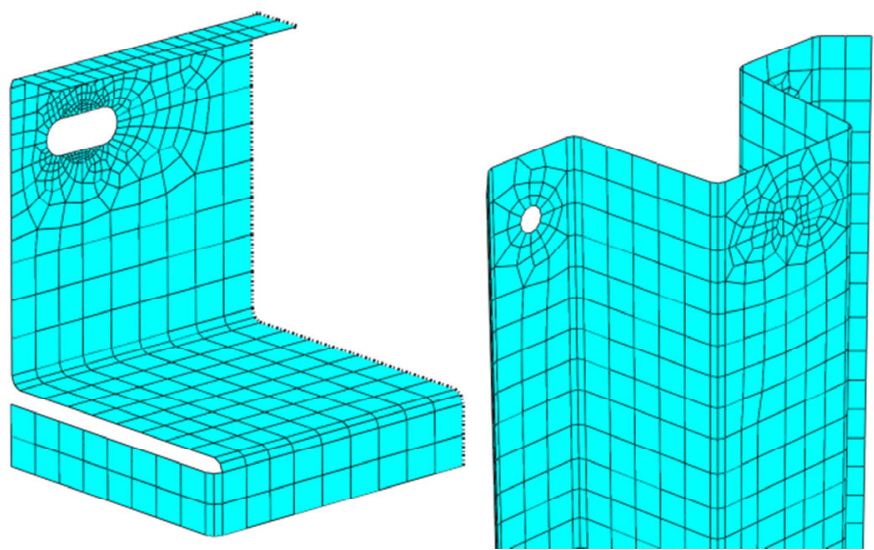

Fig. 5. The mesh in numerical model of cassette and Omega profile with mesh size $6 \mathrm{~mm}$.

\section{Numerical analysis}

As it was mentioned above, in this paper, two separate types of numerical analyses in the Abaqus program are carried out. The first refers to a fire situation and contains heat transfer and coupled thermal-structural procedure. The second analysis is provided in order to investigate the wind action influence on a thin-walled steel cladding system with respect to different blade inclination in the perforated cassette.

\subsection{Thermal analysis}

Thermal analysis starts by performing an uncoupled heat transfer procedure to obtain the temperature distribution in the steel members under the thermal loading. The analysis consists of a single transient heat transfer step. The step lasts for 15 minutes; it simulates the influence of gas temperature, using nominal temperature-time External fire curves. The initial temperature is set at $20^{\circ} \mathrm{C}$ in the entire model. The thermal response of the model is driven entirely by thermal loading using: film coefficient $\alpha_{c}=25 \mathrm{~W} / \mathrm{m}^{2} \mathrm{~K}$ - for exposed surface to hot gas; surface radiation with emissivity $\varepsilon_{m}=0.7$ - for carbon steel. The obtained temperatures are applied to the subsequent mechanical analysis as a predefined temperature field. The static step is performed to simulate the mechanical response of the model exposed to parametric fire and lasts for 5 minutes. The initial temperature is assumed equal to $20^{\circ} \mathrm{C}$ in the entire model. The Newton Raphson method is used as a numerical technique for solving the nonlinear equilibrium equations.

\subsection{Wind action on perforated cassette}

For the numerical analysis a characteristic wind load value for the building of the centre "Wroclavia" with dimensions $230 \times 280 \times 25 \mathrm{~m}$ (length $\times$ width $\times$ height) was adopted based on Eurocode [9]. For first wind load zone in Poland, the value of the base wind speed is $v_{b, 0}=26[\mathrm{~m} / \mathrm{s}]$. Therefore, the wind pressure on the external surfaces of the building equals $830[\mathrm{~Pa}]$. The wind acts on the inclined parts of the cassette in the form of components in the perpendicular and longitudinal direction to the plane of the element, as shown in Fig. 6. 
a)

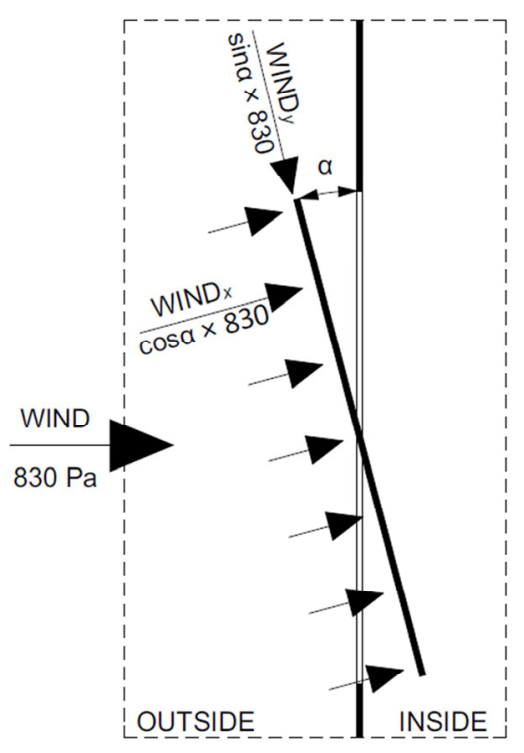

b)

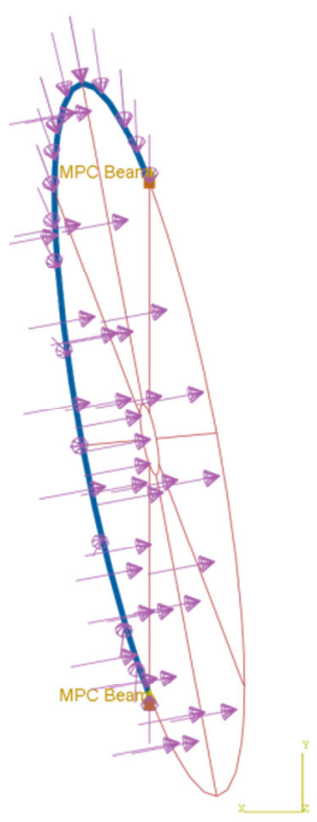

Fig. 6. Wind action: a) static scheme; b) numerical model.

Table 1 presents the values of components of the wind pressure vector depending on the angle of blade's inclination.

Table 1. Components of the wind pressure vector.

\begin{tabular}{|c|c|c|}
\hline $\boldsymbol{\alpha}\left[^{\boldsymbol{}}{ }^{\boldsymbol{}}\right]$ & $\mathbf{W I N D}_{\boldsymbol{X}},[\boldsymbol{P a} \boldsymbol{]}$ & $\mathbf{W I N D}_{\boldsymbol{Y}},[\boldsymbol{P a} \boldsymbol{]}$ \\
\hline 15 & 802 & 215 \\
\hline 30 & 718 & 415 \\
\hline 45 & 586 & 586 \\
\hline
\end{tabular}

\section{Numerical results}

\subsection{Results of heat transfer analysis}

Results of uncoupled thermal analysis refer to the temperature distribution in the tested structural elements. The heating process of the individual structural elements depending on time is developed according the nominal temperature-time External fire curve which describes the gas temperature. One can notice that the cassette, made of very thin steel sheet with a thickness of $1.2 \mathrm{~mm}$, being subjected to a rapid increase in the temperature and after 10 minutes the temperature is at $655^{\circ} \mathrm{C}$ and almost coincides with the gas temperature. Next due to direct contact, the cassette affects the substructures by means of conduction and radiation of the heated surface. Thus the temperature of the Omega profile also achieves a high temperature heating. This phenomena is shown in Figure 7. The maps of temperature distribution in model in case of External fire action after 10 minutes are shown in Fig. 8a for whole structure and in Fig. $8 \mathrm{~b}$ for substructure made of Omega profiles. 


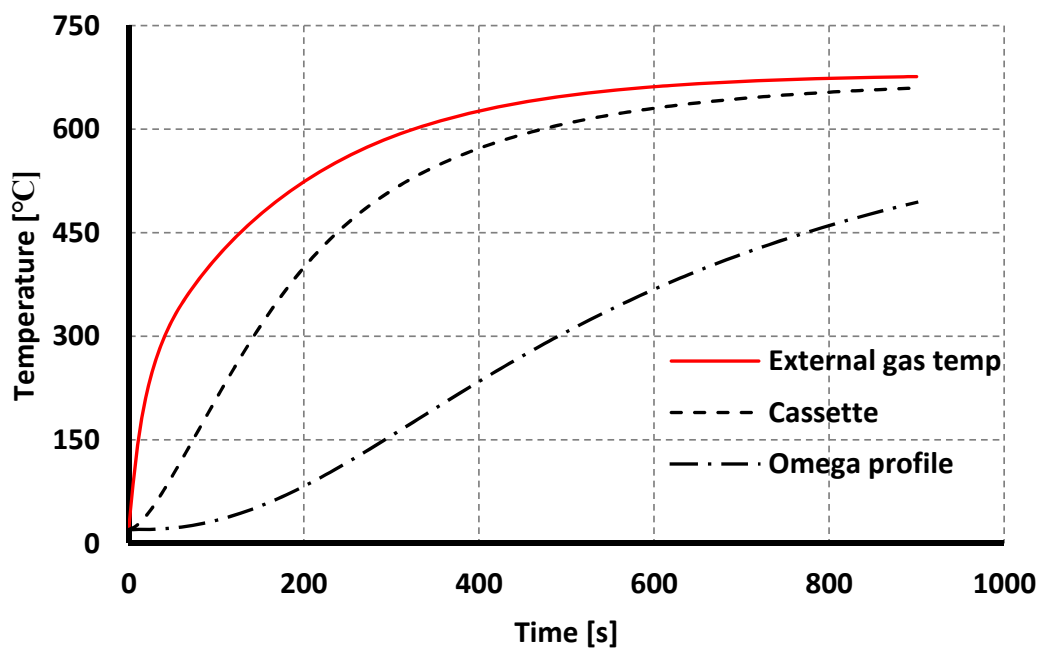

Fig. 7. Temperature - Time relationship in model of External fire curve.

a)

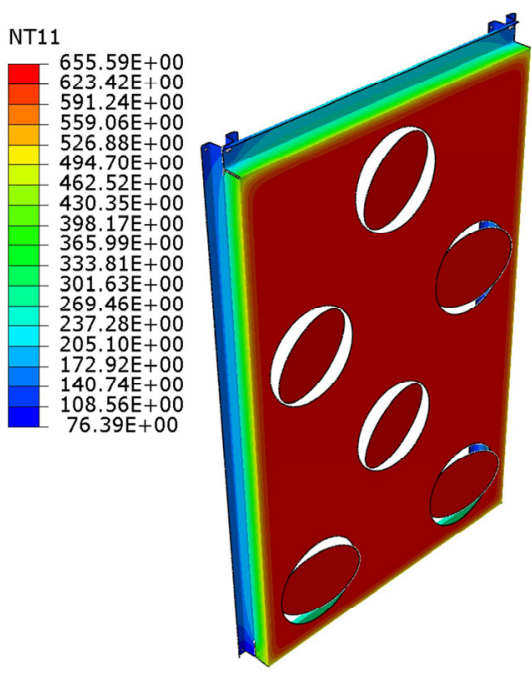

b)

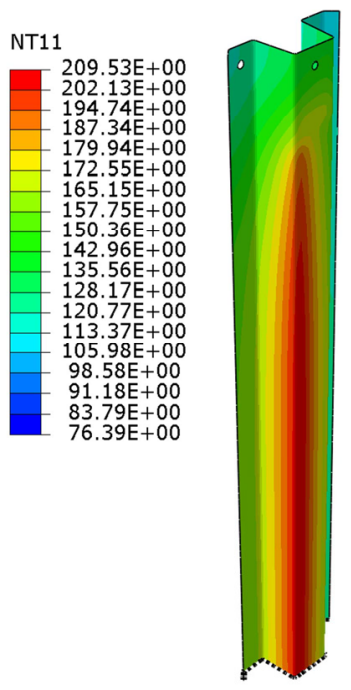

Fig. 8. Temperature distribution in model in case after 10 minutes of being exposed to external fire a) assembly; b) Omega profiles.

\subsection{Results of Thermal-Stress analysis}

Based on temperature distribution obtained from heat transfer analysis the temperature field for static analysis was predefined. The mechanical response of the model exposed to parametric fire, which lasts for 5 minutes was investigated. The results of the analysis obtained for 5 minutes of being exposed to fire are presented in Fig. 9. Such a short time was enough that in places marked in red, stresses exceed the limits of plasticity namely $286 \mathrm{MPa}$. It can be seen that in the case of perforation type A with the inclination of $\alpha=15^{\circ}$ the stress concentration zone was notably larger than in the case of perforation type B. 
a)

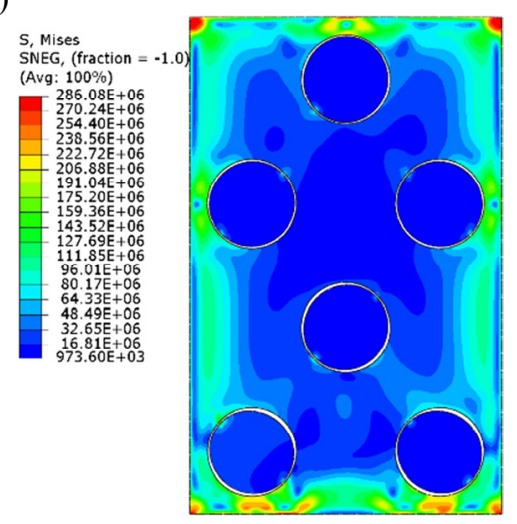

b)

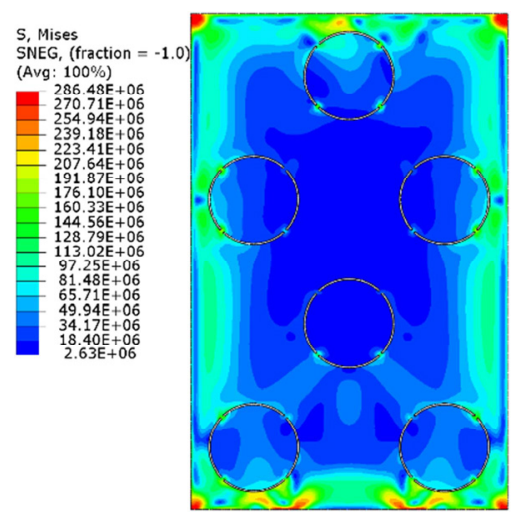

Fig. 9. Mises Stress from thermal-stress analysis in type of perforation: a) type $A \alpha=15^{\circ}$; b) type B.

\subsection{Results of static analysis}

In order to investigate structural behaviour of the cassettes in a normal situation, the static analysis under the wind pressure with respect to a different inclination of blades; is performed. Figure 10 shows influence of perforation type and blade inclination on the cassettes Mises stress distribution corresponding with wind pressure of $830[\mathrm{~Pa}]$.

a)

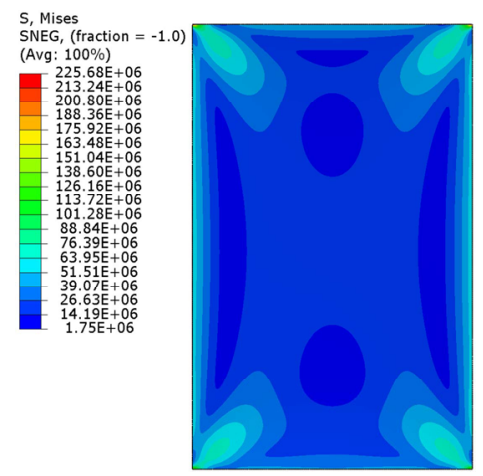

c)

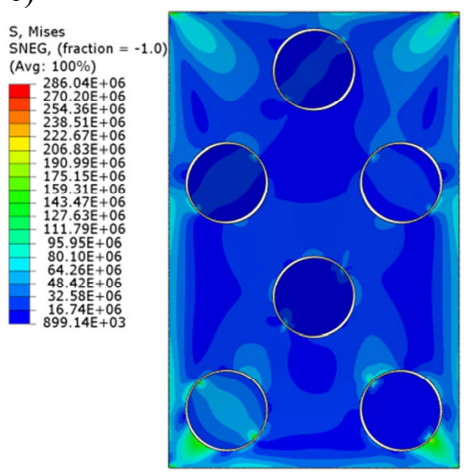

b)

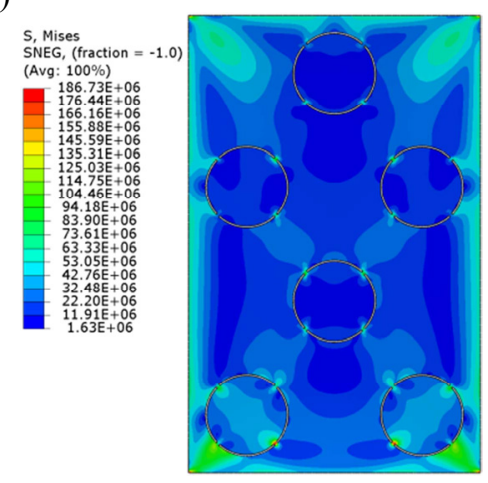

e)

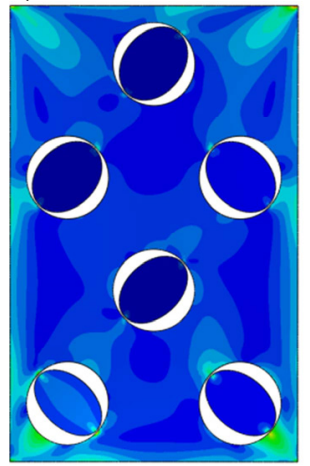

Fig. 10. Mises stress distribution from static analysis for different type of perforation: a) type $C$; b) type $\mathrm{B}$, c) type $\mathrm{A} \alpha=15^{\circ}$; d) type $\mathrm{A} \alpha=30^{\circ}$; e) type $\mathrm{A} \alpha=45^{\circ}$. 
Basis on static analysis with respect to wind pressure, it can be stated that perforation causes some increase in stresses in relation to the non-perforated cassette. The worst behaviours are observed for the perforated cassettes of the type A. Stresses in the cassette subjected to the wind reach the limit of plasticity in places where the cassette changes shape, i.e. the corners of the panels. The angle of blade inclination influences locally the stress concentration in places where perforated parts are connected to the panel. On the other hand, globally, the increase in angle of the blade's rotation influences the increase in deflections. The reason for this is the increase in the wind pressure vector WIND $_{\mathrm{Y}}$. The maximum deflection of the cassette under the wind load is summarized in Table 2.

Table 2. The maximum deflection of the cassette under the wind load.

\begin{tabular}{|c|c|c|c|}
\hline \multirow{2}{*}{$\boldsymbol{\alpha}\left[^{\boldsymbol{}}{ }^{\circ}\right]$} & \multicolumn{3}{|c|}{ Maximum deflection [mm $]$} \\
\cline { 2 - 4 } & Type A & Type B & Type C \\
\hline 0 & $\mathrm{x}$ & 12.8 & 11.3 \\
\hline 15 & 15.8 & $\mathrm{x}$ & $\mathrm{x}$ \\
\hline 30 & 16.7 & $\mathrm{x}$ & $\mathrm{x}$ \\
\hline 45 & 17.6 & $\mathrm{x}$ & $\mathrm{x}$ \\
\hline
\end{tabular}

The influence of type of numerical analysis is visible in the deformation within the lock region (Fig. 11) or within the perforation zone (Fig. 12).

a)

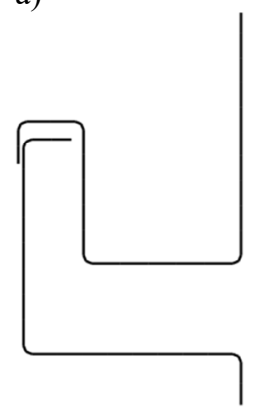

b)

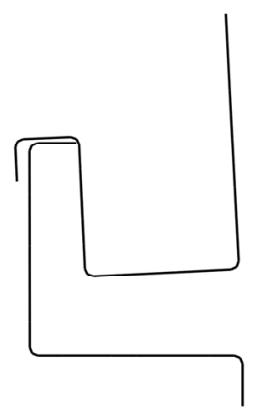

c)

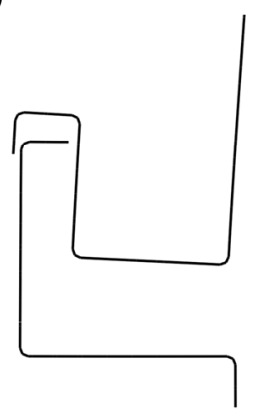

Fig. 11. Details of deformation of the bottom lock: a) before analysis; b) Structural analysis/wind action; c) Thermal-stress analysis.
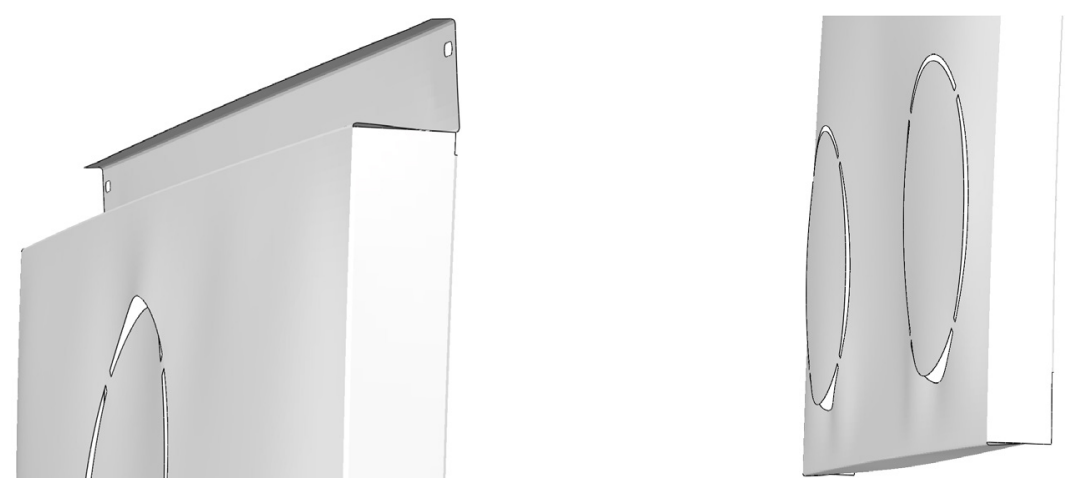

Fig. 12. Details of deformation after Thermal-Stress analysis in cassette with perforation type B. 


\section{Conclusion}

In the paper, numerical analysis of thin-walled steel cassettes with perforation in normal and in fire situations was carried out. Particular attention was focused on the analysis of the influence of blade inclination and perforation pattern on the structural behaviour. As regards the heat transfer analysis, it was found that the cassette, due to the very thin wall, heats up almost the same as gas, and after 10 minutes get temperature of $655^{\circ} \mathrm{C}$. Thermal-stress analysis showed that after 2.5 minutes of fire action in local zones of cassette stresses exceed the limits of plasticity. It was found, that in the case of perforation type A with the inclination of $\alpha=15^{\circ}$ the stress concentration zone was notably larger than in the case of perforation type B. I was also assumed that in the fire conditions due to thermal expansion and material degradation, cassettes demonstrate significant deformation in, and out of plane. As regards static analysis with respect to wind pressure, it was stated that perforation causes some increase in stresses in relation to the non-perforated cassette. In each of analysed model, it was observed that one of the weakest parts of the facade system is the connection. Therefore, in the future work, authors intend to conduct laboratory tests and numerical analysis to describe phenomena occurring in that part.

Acknowledgement. Financial support by the DS grant 01/11/DSPB/0006 Poznan University of Technology, and company „Blachy Pruszyński” is kindly acknowledged. This research was supported in part by PLGrid Infrastructure.

\section{References}

1. P. Lewandowski, E. Urbanska-Galewska, IMOGEOR, 5, 518, (2014)

2. P. Lewandowski, E. Urbanska-Galewska, JCEEA, 58, 265, (2011)

3. W. Lu, P. Makelainen and J. Outinen, JOCBT, 4, 28, (2007)

4. W. Lu, P. Makelainen and J. Outinen, JSM, 2, 257, (2008)

5. J.-M. Franssen, R.P. Vila, "Fire Design in Steel Structures" (ECCS Eurocode Design Manuals, 2015)

6. DIFISEK, Dissemination of Fire Safety Engineering Knowledge, Poznan University of Technology, (2008)

7. D.C. Helder, P.C.R. Joao, S. Aldina, L. Luis, TWS, 98, 154, (2016)

8. EN 1993-1-2, Eurocode 3. Design of steel structures - Part 1-2. General rules - Structural fire design. CEN, Brussels, (2005)

9. EN 1991-1-4, Eurocode 1. Actions on structures - Part 1-4: General actions - Wind actions. CEN, Brussels (2005). 